\title{
First Light-Emitting Neutral Molecular Rectangles
}

\section{T. Rajendran, ${ }^{\dagger, \not}$ Bala Manimaran, ${ }^{\dagger}$ Fang-Yuan Lee, ${ }^{\dagger}$ Gene-Hsiang Lee, ${ }^{\S}$ Shie-Ming Peng, ${ }^{\S}$ Chong Mou Wang, ${ }^{\prime \prime}$ and Kuang-Lieh Lu*,†}

Institute of Chemistry, Academia Sinica, Taipei 115, Taiwan, ROC, Department of Chemistry, National Taiwan University, Taipei 107, Taiwan, ROC, and Department of Chemistry, National Taiwan Normal University, Taipei 117, Taiwan, ROC

Received October 25, 1999

Supramolecular structures containing transition metal ions with potential inclusion and host-guest applications have been extensively explored in recent years. ${ }^{1-4}$ Stang and co-workers contributed to the formation of a combinatorial library of cyclic molecular polygons via the systematic combination of building blocks with predetermined angles. ${ }^{5}$ The initial focus was directed toward molecular squares, i.e., macrocycles fabricated by ciscoordinated transition metal corners and rigid or semirigid bifunctional ligand edges. ${ }^{6-8}$ Subsequent efforts were devoted to the synthesis of molecular rectangles to improve selectivity and sensitivity in molecular recognition and separation. ${ }^{9-12}$ Hupp et al. were the first to report the preparation of rhenium thiolatebased rectangles that exhibited interesting electrochemistry. ${ }^{9,10}$ Subsequent work by the same group led to the synthesis, characterization, and preliminary binding properties of a new class of tetracationic rectangular molecules with triflate as counterion. ${ }^{10}$ To tune the cavity size, Sullivan et al. recently also reported the

* To whom correspondence should be addressed. Fax: international code + (2)27831237. E-mail: lu@chem.sinica.edu.tw.

${ }^{\dagger}$ Academia Sinica.

* Permanent Address: Department of Chemistry, Vivekananda college, Tiruvedakam West, Madurai, 625 217, India.

$\S$ National Taiwan University.

"National Taiwan Normal University.

(1) (a) Stang, P. J.; Fan, J.; Olenyuk, B. J. Chem. Soc., Chem. Commun. 1997, 1453-1454. (b) Stang, P. J.; Cao, D. H.; Saito, S.; Arif, A. M. J. Am. Chem. Soc. 1995, 117, 6273-6283. (c) Stang, P. J.; Whiteford, J. A. Organometallics 1994, 13, 3776-3777.

(2) Caulder, D. L.; Raymond, K. N. J. Chem. Soc., Dalton Trans. 1999, $1185-1200$.

(3) (a) Fujita, M.; Ogura, K. Bull. Chem. Soc. Jpn. 1996, 69, 1471-1482. (b) Fujita, M.; Yazaki, J.; Ogura, K. Tetrahedron Lett. 1991, 32, 55895592.

(4) (a) Lehn, J.-M. Supramolecular Chemistry: Concepts and Perspectives; VCH: Weinheim, 1995. (b) Drain, C. M.; Lehn, J.-M. J. Chem. Soc. Chem. Commun. 1994, 2313-2315.

(5) Olenyuk, B.; Fechtenkotter, A.; Stang, P. J. J. Chem. Soc., Dalton Trans. 1998, 1707-1728.

(6) (a) Fan, J.; Whiteford, J. A.; Olenyuk, B.; Levin, M. D.; Stang, P. J.; Fleischer, E. B. J. Am. Chem. Soc. 1999, 121, 2741-2752. (b) Stang, P. J.; Olenyuk, B. Angew. Chem., Int. Ed. Engl. 1996, 35, 732-736. (c) Stang, P. J.; Olenyuk, B. Acc. Chem. Res. 1997, 30, 502-518.

(7) (a) Belanger, S.; Hupp, J. T.; Stern, C. L.; Slone, R. V.; Watson, D. F.; Carrell, T. G. J. Am. Chem. Soc. 1999, 121, 557-563. (b) Slone, R. V.; Benkstein, K. D.; Belanger, S.; Hupp, J. T.; Guzei, I. A.; Rheingold, A. L. Coord. Chem. Rev. 1998, 171, 221-243. (c) Slone, R. V.; Yoon, D. I.; Calhoun, R. M.; Hupp, J. T. J. Am. Chem. Soc. 1995, 117, 1181311814.

(8) Sun, S.-S.; Lees, A. J. Inorg. Chem. 1999, 38, 4181-4182.

(9) Benkstein, K. D.; Hupp, J. T.; Stern, C. L. Inorg. Chem. 1998, 37, 54045405.

(10) Benkstein, K. D.; Hupp, J. T.; Stern, C. L. J. Am. Chem. Soc. 1998, 120, 12982-12983.

(11) Slone, R. V.; Hupp, J. T.; Stern, C. L.; Schmitt, T. E. A. Inorg. Chem. 1996, 35, 4096-4097.

(12) Woessner, S. M.; Helms, J. B.; Shen, Y.; Sullivan, B. P. Inorg. Chem. 1998, 37, 5406-5407.

(13) Crystal data for 3a: monoclinic, space group $=P 2_{1} / \mathrm{c}, a=12.0890(2)$ $\AA, b=24.2982(2) \AA, c=12.8721(2) \AA, \beta=107.923(1)^{\circ}, V=3597.57-$ (9) $\AA^{3}, \rho=2.051 \mathrm{Mg} / \mathrm{m}^{3}, Z=2, T=150 \mathrm{~K}$; of 18370 reflections $(2 \theta$ $<52^{\circ}$ ) measured, 7285 with $I>2 \sigma(I)$ were used to refine 451 parameters. $R=0.0356$ and $w R\left(F^{2}\right)=0.0693$.

\section{Scheme 1}
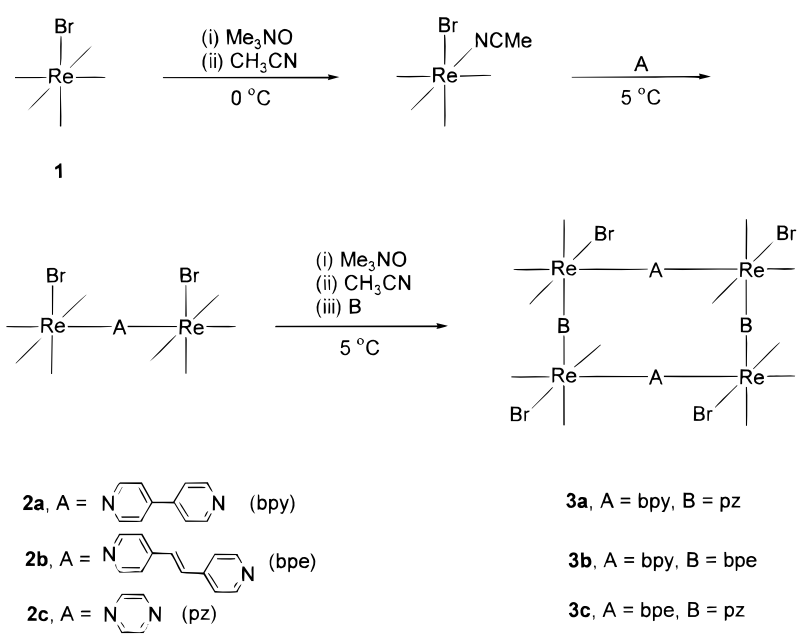

preparation of a series of molecular rectangles based on fac-Re(CO) $)_{3}$ corners containing 4,4'-bipyridine as one side and two $\eta^{2}$ alkoxy or hydroxy bridges as the other. ${ }^{12}$

We report herein the synthesis and characterization of a new class of molecular rectangles $\mathbf{3}$ (Scheme 1) that exhibit luminescence in solution at room temperature. Unlike earlier "rectangles", compounds $\mathbf{3}$ are neutral, possess larger cavities, and have no counterions inside the channels.

Activation of $\operatorname{Re}(\mathrm{CO})_{5} \mathrm{Br}(\mathbf{1})$ with $\mathrm{Me}_{3} \mathrm{NO}$ at $0{ }^{\circ} \mathrm{C}$ followed by addition of 0.5 equiv of $4,4^{\prime}$-bipyridine in toluene gave a paleyellow, shiny product $\left\{\operatorname{Re}(\mathrm{CO})_{4} \mathrm{Br}\right\}_{2}(\mu$-bpy) (2a) in $58 \%$ yield. Further treatment of $\mathbf{2 a}$ at $5{ }^{\circ} \mathrm{C}$ in $\mathrm{CH}_{2} \mathrm{Cl}_{2}$ with 2 equiv of $\mathrm{Me}_{3^{-}}$ $\mathrm{NO}$ and a required amount of acetonitrile yielded intermediate$\left\{\left(\operatorname{Re}(\mathrm{CO})_{3}(\mathrm{NCMe}) \mathrm{Br}\right\}_{2}(\mu\right.$-bpy $)$, which produced the molecular rectangle 3a (14\% yield) after subsequent titration with pyrazine. Following a similar strategy, the bimetallic edges $\mathbf{2 b}$ and $\mathbf{2 c}$ were synthesized from trans-1,2-bis(4-pyridyl)ethylene and pyrazine, respectively. Compounds $\mathbf{2} \mathbf{a}$ and $\mathbf{2} \mathbf{b}$ were then converted into $\mathbf{3 b}$ and $3 \mathbf{c}$ by reacting with trans-1,2-bis-(4-pyridyl)ethylene and pyrazine, respectively.

Rectangles $\mathbf{3}$ and their corresponding edges $\mathbf{2}$ were characterized spectroscopically. The FAB-MS analyses of $\mathbf{3 a}$ and $\mathbf{2 a}$ exhibit signals corresponding to the molecular ions at $\mathrm{m} / \mathrm{z}=1880$ and $m / z=916$, respectively, with the experimental isotope pattern matching the calculated values. The ${ }^{1} \mathrm{H}$ NMR spectrum of $\mathbf{3 a}$ shows the presence of two predominant isomeric forms in solution at room temperature, most likely due to the orientation of the $\mathrm{CO} / \mathrm{Br}$ trans-ligand pairs with respect to the plane containing the Re atoms.

Yellow single crystals of $\mathbf{3 a}$ were grown from acetone, and X-ray diffraction studies were carried out. ${ }^{13}$ An ORTEP diagram of $\mathbf{3 a}$ is shown in Figure 1. The structure consists of a molecular rectangle in which two $\mathrm{Br}(\mathrm{CO})_{4} \mathrm{Re}-$ bpy $-\mathrm{Re}(\mathrm{CO})_{4} \mathrm{Br}$ edges are 


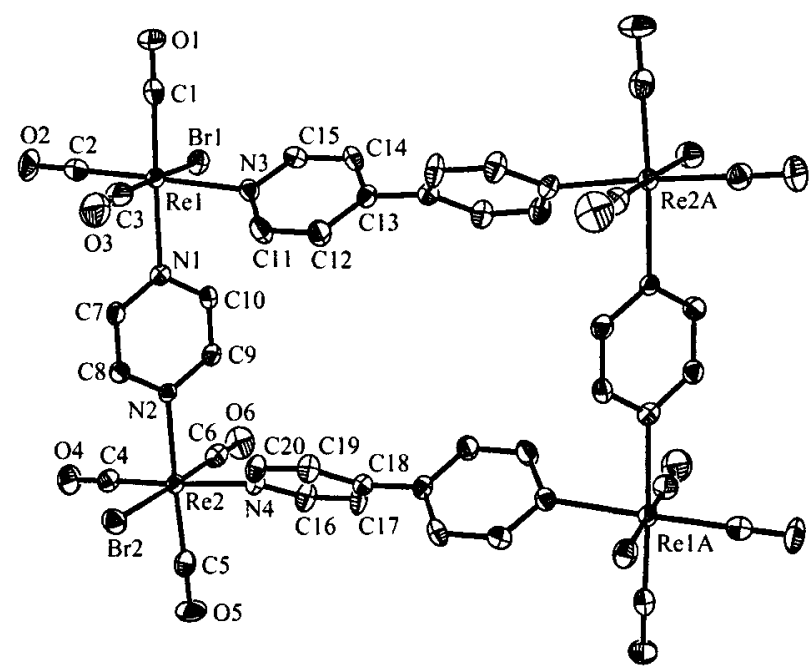

Figure 1. ORTEP diagram of 3a. Selected bond distances $(\AA)$ and angles (deg) are the following: $\operatorname{Re}(1)-\mathrm{N}(1) 2.212(5), \operatorname{Re}(1)-\mathrm{N}(3) 2.221(5)$, $\operatorname{Re}(1)-C(1)$ 1.929(7), $\operatorname{Re}(1)-C(2)$ 1.922(6), $\operatorname{Re}(1)-C(3)$ 1.92(2), Re(2) $-\mathrm{N}(2) 2.212(4), \operatorname{Re}(2)-\mathrm{N}(4) 2.218(5), \operatorname{Re}(2)-\mathrm{C}(4)$ 1.919(6), $\operatorname{Re}(2)-$ $\mathrm{C}(5)$ 1.924(7), $\operatorname{Re}(2)-\mathrm{C}(6)$ 1.92(1), N(1)-Re(1)-N(3) 84.5(2), N(2)$\operatorname{Re}(2)-\mathrm{N}(4)$ 82.4(2).

bridged by two pyrazine moieties. In each bipyridine moiety, one of the aromatic rings is found to have a canted configuration with respect to the plane of other rings. The $\operatorname{Br}(1)$ and $\operatorname{Br}(2)$ are disordered with the CO group in $73 / 27$ occupancy, which is substantiated by the isomeric ${ }^{1} \mathrm{H}$ NMR spectral pattern of $\mathbf{3 a}$. Average bond distances are as follows: $\mathrm{Re}-\mathrm{C}(\mathrm{CO}), 1.92 \AA$; $\mathrm{Re}-$ $\mathrm{N}\left(4,4^{\prime}\right.$-bpy), $2.22 \AA ; \mathrm{Re}-\mathrm{N}(\mathrm{pz}), 2.21 \AA$. They are similar to those found for a number of other Re(I) complexes. ${ }^{7 a, b, 12}$ The molecular rectangle $3 \mathbf{a}$ consists of a cavity with the dimensions of $11.44 \AA$ $\times 7.21 \AA$. Since no steric hindrance exists between the Re metal centers, fine-tuning of the cavity size is possible. For example, in $\mathbf{3 b}$, a cavity with dimensions of $11.38 \AA \times 13.17 \AA$ could be achieved, as revealed by molecular modeling. The packing diagram of 3a shows the effective $\pi$ staking of the aromatic rings that ensures the close packing of the molecules to form an infinite number of open-end channels.

IR spectroscopy showed that the CO stretching $\left(v_{\mathrm{CO}}\right)$ shifted bathochromically from 2113 to $2032 \mathrm{~cm}^{-1}$ when $\mathbf{2 a}$ was converted into 3a. This red shift in $v_{\mathrm{CO}}$ indicates that new linkages are formed between the additional $\pi$ ligands and the metal center. In addition, compounds $\mathbf{2}$ and $\mathbf{3}$ exhibit two absorption bands in the near-UV region. We attribute the absorption band at higher energy $(251-265 \mathrm{~nm})$ to a $\pi-\pi^{*}$ transition and the lower one $(315-$ $342 \mathrm{~nm}$ ) to the MLCT transition. ${ }^{14-16}$ Control experiments showed that the MLCT bands of $\mathbf{2}$ or $\mathbf{3}$ are insensitive to the variation of the halide, ${ }^{14}$ whereas a substitution of $\mathrm{CO}$ with other ligands would

(14) Giordano, P. J.; Wrighton, M. S. J. Am. Chem. Soc. 1979, 101, 28882897.

(15) Kalyanasundaram, K. Photochemistry of polypyridine and porphyrin complexes; Academic Press: London, 1992.

(16) Meyer, T. J. Pure Appl. Chem. 1986, 58, 1193-1206.

(17) Sahai, R.; Rillema, D. P.; Shaver, R.; Wallendael, S. V.; Jackman, D. C.; Boldaji, M. Inorg. Chem. 1989, 28, 1022-1028.

(18) Lees, A. J. Chem. Rev. 1987, 87, 711-743.

(19) Baitalik, S.; Florke. U.; Nag, K. Inorg. Chem. 1999, 38, 3296-3308.
Table 1. Electronic Absorption Maxima, Excited-State Emission Maxima, Emission Lifetimes, and Emission Quantum Yields

\begin{tabular}{|c|c|c|c|c|c|c|}
\hline no. & complex & $\begin{array}{c}\lambda_{\max } \\
(\mathrm{nm})^{a} \\
\text { LIG }\end{array}$ & $\begin{array}{c}\lambda_{\max } \\
(\mathrm{nm})^{a} \\
\text { MLCT }\end{array}$ & $\begin{array}{c}\lambda_{\max } \\
(\mathrm{nm})^{a} \\
\mathrm{Em}\end{array}$ & $\begin{array}{c}\tau \\
(\mathrm{ns})^{a}\end{array}$ & $\Phi_{\mathrm{em}}^{b}$ \\
\hline $2 \mathbf{a}$ & $\{\operatorname{Re}(\mathrm{C}$ & 263 & 315 & 412,563 & 228 & 0.0017 \\
\hline $2 \mathbf{b}$ & $\left\{\operatorname{Re}(\mathrm{CO})_{4} \mathrm{Br}\right\}_{2}(\mu-\mathrm{b}$ & 265 & 320 & 452 & 16 & 0.0031 \\
\hline $2 c$ & $\left\{\operatorname{Re}(\mathrm{CO})_{4} \mathrm{Br}\right\}_{2}(\mu-\mathrm{pz})$ & 262 & 322 & 541 & 17 & 0.0014 \\
\hline 3a & $\begin{array}{l}{\left[\left\{\operatorname{Re}(\mathrm{CO})_{3}(\mu-\text { bpy }) \mathrm{Br}\right\}\right.} \\
\left\{\operatorname{Re}(\mathrm{CO})_{3}(\mu \text {-pz)Br}\}\right]_{2}\end{array}$ & 254 & 324 & 416,563 & 14 & 0.0010 \\
\hline $\mathbf{3 b}$ & $\begin{array}{l}{\left[\left\{\operatorname{Re}(\mathrm{CO})_{3}(\mu \text {-bpy }) \mathrm{Br}\right\}\right.} \\
\left.\left\{\operatorname{Re}(\mathrm{CO})_{3}(\mu \text {-bpe }) \mathrm{Br}\right\}\right]_{2}\end{array}$ & 252 & 329 & 467 & 11 & 0.0014 \\
\hline $3 c$ & $\begin{array}{l}{\left[\left\{\operatorname{Re}(\mathrm{CO})_{3}(\mu \text {-bpe }) \mathrm{Br}\right\}\right.} \\
\left.\left\{\operatorname{Re}(\mathrm{CO})_{3}(\mu \text {-pz }) \mathrm{Br}\right\}\right]_{2}\end{array}$ & 251 & 342 & $\begin{array}{l}385,470 \\
558\end{array}$ & 15 & 0.00 \\
\hline
\end{tabular}

${ }^{a}$ Measured in deoxygenated $\mathrm{CH}_{3} \mathrm{CN}$ at $298 \mathrm{~K} .{ }^{b}$ Emission quantum yield measured at $298 \mathrm{~K}$. $\lambda_{\mathrm{ex}}=436 \mathrm{~nm}$ with reference to $\left[\mathrm{Ru}(\mathrm{bpy})_{3}\right]^{2+}$ $\left(\Phi_{\mathrm{em}}=0.0420\right)$; error is $\pm 10 \%$.

shift the MLCT band bathochromically. Examination of the UVvis absorption spectra showed that the MLCT maximum of $\mathbf{2 a}$ is centered at $315 \mathrm{~nm}$, whereas for $\mathbf{3 a}$ it is at $324 \mathrm{~nm}$. This spectral difference suggests that the ground state of $\mathbf{2} \mathbf{a}$ has been raised to a higher level after conversion to $\mathbf{3 a}$.

Because compounds $\mathbf{2}$ and $\mathbf{3}$ were brought to their MLCT excited states photochemically, both molecules fluoresced with quantum yield of ca. 0.002 relative to $\mathrm{Ru}(\mathrm{bpy})_{3}{ }^{2+} \cdot{ }^{17-19}$ The lifetimes measured for $\mathbf{2}$ and $\mathbf{3}$ are on the order of nanoseconds (Table 1). On the other hand, cyclic voltammetry revealed that electron exchange through an electrode such as glassy carbon occurred near the potential of $E \geq 1.0 \mathrm{~V}$ vs SCE. Therefore, compounds $\mathbf{2}$ and $\mathbf{3}$ are expected to be strong reducing agents upon photoexcitation. Combining the energy gap between the ground state and the MLCT excited state as well as the formal potentials of $\mathbf{3}^{+/ 0}$, we estimated formal potentials for $\mathbf{3}$ at their excited states of about $-1 \mathrm{~V}$ vs SCE. Thus, these compounds are capable of reducing methyl viologen $\left(\mathrm{MV}^{2+}, E^{0^{\prime}}{ }_{1} \approx-0.4 \mathrm{~V}\right.$; $E^{0^{\prime}}{ }_{2} \approx-0.7 \mathrm{~V}$ vs SCE) or tetracyanoquinodimethane (TCNQ, $E^{0^{\prime}} \approx-0.3 \mathrm{~V}$ vs SCE). Preliminary results with $\mathbf{3 a}$ are in full accord with this hypothesis. The excited state of $\mathbf{3 a}$ can be oxidatively quenched by TCNQ; the Stern-Volmer quenching rate constant is estimated to be $10^{5} \mathrm{M}^{-1} \mathrm{~s}^{-1}$ at $25^{\circ} \mathrm{C}$.

Further experiments showed that these molecular rectangles can form thin films on many electrodes, such as gold and glassy carbon, and showed interesting ability to differentiate substrates of different sizes. With these unique properties, rectangles 3 should find many applications, including ultrafiltration, molecular separation, and optical rectification.

Acknowledgment. We thank Academia Sinica and the National Science Council of the Republic of China for financial support. We are also grateful to Professor Sunney I. Chan for valuable discussions.

Supporting Information Available: Experimental details, tables listing molecular modeling data of interatomic distances (Re $\cdots \mathrm{Re}$ ), electrochemical data, crystallographic data, isotopic distribution patterns of the $\mathrm{M}^{+}$peaks for $\mathbf{2 a}$ and 3a, packing diagram of $\mathbf{3 a}$. This material is available free of charge via the Internet at http://pubs.acs.org.

IC9912474 